\title{
Domestic regulation, international standards, and technical barriers to trade
}

\author{
JAN MCD O NA L D* \\ Griffith Law School, Griffith University, Queensland, Australia
}

\begin{abstract}
There is growing concern over the use of domestic product regulations as technical barriers to trade on the one hand, and the WTO's incursion into domestic regulatory autonomy on the other. The TBTA seeks to balance competing interests - acknowledging but disciplining Members' regulatory control over traded goods. The effectiveness of these disciplines is limited by the exclusion of many modern domestic regulations from the scope of the TBTA; the surest way to prevent abuse of process-based product specifications is to subject them to the TBTA's disciplines. The WTO dispute settlement tribunals have affirmed the importance of the use or adoption of international standards. While Members are still entitled to introduce their own measures in some circumstances, the emphasis on international standards raises the status of standard-setting bodies. Despite their important new role, the composition, accountability, and decision-making procedures have so far escaped the kind of civil society scrutiny to which WTO deliberations are now subject. To achieve the TBTA's harmonization objectives, the development, and use of international standards and their legal recognition within the WTO regime should be revised to safeguard legitimate non-trade regulatory objectives.
\end{abstract}

\section{Introduction}

The relationship between the international trade regime and social, environmental, and health policies has received unprecedented diplomatic and scholarly analysis in the past decade. The WTO Appellate Body has affirmed the WTO regime's capacity to accommodate such relationships, especially under the GATT (Howse, 2002; Trachtman, 2003a), but this progress does not signal the end of the 'linkage' debate. Concerns about the WTO's tolerance of national regulatory choices are reflected in the response of some Members to the AB's linkage jurisprudence and the slow progress of Committee on Trade and Environment negotiations. Meanwhile, civil society remains concerned about the WTO's impact on domestic

\footnotetext{
* Email: jan.mcdonald@griffith.edu.au. This paper builds upon 'Non-Economic Factors in the Agreement on Technical Barriers to Trade: Social and Environmental Policy, Harmonization, and Regulatory Sovereignty' presentation to the 'Why Have a World Trade Organization? Symposium, Adelaide, 25 February 2004. The author gratefully acknowledges the comments of anonymous referees and members of the WTR editorial board. All remaining errors and omissions are those of the author.
} 
regulatory autonomy, shifting its focus somewhat away from trade in goods to the social, environmental and cultural implications of services liberalization under the GATS negotiations.

This paper contributes to recent legal and policy analyses of regulatory barriers to trade (Marceau and Trachtman, 2002; Picciotto, 2003; Trachtman, 2003a), by examining the WTO Agreement on Technical Barriers to Trade's (TBTA) emphasis on international standards as a harmonization mechanism. Considerable scholarly attention has been devoted to the TBTA's companion agreement dealing with food safety and plant and animal health, the Agreement on Sanitary and Phytosanitary Measures (the SPSA) (e.g. Christoforou, 2000; Howse, 2000; Victor, 2000; Robertson and Kellow, 2001), but the TBTA has received relatively scant appraisal. ${ }^{1}$ The SPSA disciplines were tested soon after the Agreement's introduction and have been considered several times since (Hormones AB; Salmon $\mathrm{AB}$; Varietals AB; Apples AB), but neither the TBTA nor its predecessor the Standards Code had been subject to dispute settlement analysis until 2000. Indeed, the first detailed consideration and application of the TBTA's substantive provisions did not emerge until the 2002 Sardines decision.

A number of factors may explain the lower level of interest in the TBTA. Firstly, the TBTA merely superceded an existing agreement - it was not a wholly new undertaking when the WTO Agreement became operational. Secondly, as a general observation it is fair to say that the subject matter of measures disciplined by the TBTA is less politically sensitive or culturally embedded than those under the SPSA. A corollary of this is that SPS measures seem to have been particularly exploited as a means of protecting domestic industries, thereby justifying a larger number of complaints and disputes. Finally, the SPSA introduced a significant new discipline in emphasizing science and risk assessment as a guiding discipline-elements that demanded early clarification. Whatever the reason, the obligations of the TBTA remain largely unexplored, despite growing concern about the impacts of standards as technical barriers to trade (Maskus and Wilson, 2000). ${ }^{2}$ These concerns come from both sides: developing countries, who must comply with potentially discriminatory burdensome domestic measures and who are largely absent from international standards organizations; and environmental, consumer or other non-trade interest groups, whose interests lie with the preservation of national regulatory preferences. While examining the issue more broadly, the focus of this paper is on this latter concern. It considers the extent to which the TBTA's provisions for adopting international standards intrude upon domestic regulatory autonomy. Having tentatively answered that question, it considers whether this role is appropriate or justifiable, given the membership, operation, and procedures of the international standards bodies.

1 Notable exceptions include Marceau and Trachtman, 2002 and Trachtman, 2003a.

2 Maskus and Wilson note, however, that while there is considerable concern about the impacts of standards on trade, the relationships are 'ambiguous' and demand additional empirical research. 
Section 2 briefly outlines the TBTA's underlying objectives and harmonization architecture. It then outlines the scope of the TBTA's operation, highlighting the Agreement's non-application to many important domestic regulations affecting the production and sale of products. The remainder of Section 2 focuses on the TBTA's obligations dealing with international standards. Drawing upon the WTO AB's decisions in Sardines and Asbestos, and relevant related linkage jurisprudence, I discuss the implications for domestic regulation of a TBTA preference for international standards. Part 3 progresses the discussion of international standards. It highlights institutional and procedural concerns with the current operation of the TBTA's international standards provisions. The paper concludes that the number, profile, and composition of international standard-setting bodies need to be broadened; decision-making procedures should be revised; and that the WTO dispute settlement tribunals should be required to seek advice from the bodies themselves about the correct interpretation of their standards and technical regulations.

\section{The TBTA and international standards}

\subsection{The TBTA's harmonization objectives}

It has long been accepted that domestic policies and laws can nullify or impair the purported benefits of trade policies, and that the WTO must therefore reach beyond border measures (Bhagwati, 1996: 23-24). The GATT's national treatment and MFN obligations do this to some extent, but the growth in non-tariff barriers to trade during the 1960s-1970s prompted GATT parties to negotiate the Standards Code, the predecessor to the TBTA, in the Tokyo Round. The addition of the SPSA during the Uruguay Round stemmed from the failures of the Standards Code to curtail the growth in technical regulations in food and agricultural products (Marceau and Trachtman, 2002: 813-815). The TBTA and its companion on food and plant safety now add considerably to the disciplines on domestic regulatory autonomy that are contained in the GATT.

The Preamble to the TBTA sheds light on the Agreement's underlying harmonization claims. Its key trade concerns are to promote transparency by eliminating a country's ability to choose rules that have greater protective effect and to facilitate trade expansion with associated economies of scale (TBTA, Preamble; WTO CTBT, 1995, annex 4, Principle 10). These objectives do not necessarily require regulatory harmonization in the form of a single international standard or rule. If the basis of the claim for harmonization is simply to achieve economies of scale or to address transparency concerns, Cassis de Dijon makes clear that mutual recognition would be equally appropriate (Leebron, 1996; Bhagwati, 1996: 9; Bhagwati and Srinivasan, 1996: 15). But mutual recognition does not respond to concerns that the regulatory regime of another country imposes transboundary costs, hinders the implementation of domestic laws, or is somehow 'unfair' (Leebron, 1996: 94). Such concerns frequently underpin domestic regulation in fields of consumer safety and environmental health. 
Accordingly, the TBTA strives for a balance between trade facilitation and domestic regulatory objectives. Its starting premise is the right of Members to introduce product requirements that serve a range of legitimate non-trade objectives, including health, and environmental and consumer protection. In this respect, the TBTA is consistent with both trade and consumer concerns about harmonization. The Transatlantic Consumer Dialogue (TACD) 'Principles for International Harmonization', for example, advocate the preservation of cultural preferences in the field of health and safety, identifying such regulations as inappropriate subjects of harmonization (TACD, 2000, Principle 1). Unlike the TACD Principles, however, the TBTA still places strong harmonizing disciplines on the regulatory autonomy of Members in these policy spheres. These disciplines are considered further below.

\subsection{The scope of the TBTA}

The TBTA does not attempt to specify the final content of rules or requirements. Rather, it is concerned only with the reduction of difference between Members (Leebron, 1996: 42). It therefore sets general rules for how Members may develop product requirements and conformity assessment procedures for testing compliance with substantive rules. These general rules include a duty to consider adoption of international standards for products and conformity assessment procedures; a duty to participate in international standard-setting; criteria with which standards and conformity must comply when international standards are not used, such as MFN, national treatment, necessity, and least trade restrictiveness; and mutual recognition.

The significance of the TBTA's endorsement of international standards and related disciplines is obviously affected by the Agreement's reach. The TBTA is concerned with technical regulations and standards; only measures that fall within the definition of technical regulation or standard are subject to the TBTA's disciplines. If a measure does not fall within either of these definitions, its WTOconsistency is examined under either the SPSA (if the measure sets food safety, or plant or animal health requirements) or the GATT (for other restrictions on trade in goods). One might expect that Members wishing to constrain the use of trade measures as instruments of non-trade policy, or the abuse of product regulations for trade protection purposes would advocate broad definitions that lead to broad TBTA coverage. Broader subject matter coverage would supplement the arguably weaker GATT disciplines. ${ }^{3}$ The discussion below suggests, however, that the AB's current interpretation leaves many domestic regulations that indirectly affect trade in goods outside the scope of TBTA obligations.

3 TBTA coverage does not preclude the operation of the GATT, but since GATT obligations are essentially duplicated in the TBTA, albeit with differences in the burden of proof, the more relevant question is which measures are subject to the TBTA's additional more exacting disciplines. 
The TBTA disciplines mandatory and voluntary measures, the former as 'technical regulations', the latter as 'standards' (TBTA, Annex 1, 2). A technical regulation is a:

Document which lays down product characteristics or their related processes and production methods, including the applicable administrative provisions, with which compliance is mandatory. It may also deal exclusively with terminology, symbols, packaging, marking or labelling requirements as they apply to a product, process or production method. (TBTA, Annex 1, 1)

The scope of the definition of technical regulation was first clarified in the Asbestos dispute (Asbestos Panel; Asbestos AB) and applied in Sardines (Sardines Panel; Sardines AB). In Asbestos, Canada challenged France's ban on production, use, and importation of asbestos and products containing asbestos. The ban operated in conjunction with a limited number of exceptions. This ban constituted a technical regulation because it:

- applied to an identifiable product or group of products;

- set down technical characteristics; and

- was mandatory. (Asbestos AB, 66-73)

\section{Identifiable products}

Members are only able to comply with product regulations if it is clear which products are affected. Article 2.9.2 of the TBTA obliges Members to notify other Members 'of the products to be covered' by a proposed technical regulation, but this does not mean that they must be specifically identified in the regulation itself (Asbestos AB, 70; Sardines AB, 180). The group of products to which a regulation applies may be very broad, especially if the measure is couched in negative or prohibitive terms. As Asbestos shows, a prohibition on products containing asbestos fibres 'effectively prescribes or imposes certain objective features, qualities, or 'characteristics' on all products. That is, in effect, the measure provides that all products must not contain asbestos fibres' (Asbestos AB, 72). While the ban applied to a large number of products, none of which were explicitly listed, the scope of coverage was nonetheless identifiable - 'no product that might contain asbestos may do so' (Asbestos AB, 72). The exclusion of negative requirements would have produced a significant loophole in the operation of the TBTA since Members could have simply drafted measures as prohibitions to avoid its disciplines (Sardines Panel, 7.46).

In Sardines, Peru challenged Council Regulation (EEC) No. 2136/89 (the 'EC Regulation'), which laid down, among other things, marketing standards for preserved sardines. ${ }^{4}$ The EC Regulation stipulated that only one species of

4 Canada, Chile, Colombia, Ecuador, the United State and Venezuela participated in the Panel proceedings as third parties. 
fish - Sardina pilchardus Walbaum - could be named 'sardines'. It was perhaps not coincidental that pilchardus only inhabited European coastal waters. All other preserved sardine-type fish had to be called pilchards, sprats, or some other name. Sardinops sagax, which occurs mainly along the coasts of Peru and Chile, could not be identified in the European market as sardines, or even Pacific Sardines, even though the preserved product has the same appearance, smell, taste, and texture as the pilchardus species.

The EC argued that its regulation only constituted a technical regulation in respect of Sardina pilchardus so that its effect on how other species were named could not be assessed under the TBTA (EC Regulation, Article 9; Sardines Panel, 7.31). In Asbestos, however, the AB rejected a narrow approach, concluding that a measure be examined as an 'integrated whole, taking into account, as appropriate, the prohibitive and the permissive elements that are part of it' (Asbestos AB, 64). Moreover, affected products need not be expressly named, identified, or specified in the regulation (Sardines AB, 176). In Sardines, this meant that the stipulation of a positive requirement in respect of some products (i.e. that preserved sardines must contain Sardina Pilchardus) necessarily implied a correlating negative condition that it must not contain other species, which would also be caught by the TBTA.

\section{Product characteristics}

The types of 'technical characteristics' that a regulation may prescribe are also broad, but not broad enough to bring many contentious domestic regulations within the scope of the TBTA. According to the AB, 'technical characteristics' include any objectively definable 'features, qualities, attributes or other distinguishing marks' of a product. They might relate to a product's composition, size, shape, colour, texture, hardness, tensile strength, flammability, conductivity, density, or viscosity (Asbestos AB, 67). The TBTA definition would thus include product specifications for consumer safety (flammability, strength, toxicity) or environmental protection (recycled content, recyclability, re-use or other environmentally sound disposal; energy efficiency; pollution emissions; and chemical or other hazardous components). The application of the definition to genetically modified organisms remains unclear and will depend on a range of factors, including whether the gene manipulation is physically manifest in the regulated product.

While the SPSA and TBTA appear to have mutually exclusive operation, there is residual uncertainty concerning measures that stipulate characteristics to safeguard a mixture of food safety and other policy objectives. Based on Bananas (Bananas AB, 204), it is possible that the SPSA components of the measure will be considered under the SPSA (Article 1.5), but that non-SPSA components may be covered by the TBTA. This is a question currently before the Panel hearing the dispute concerning European restrictions on the import and sale of products of biotechnology (EC, 2003: 444). 


\section{PPM coverage}

From the AB's decisions to date, it may be said that technical regulations may specify performance requirements or physical product characteristics or qualities in positive or negative terms, although technical regulations must do more than simply ban certain hazardous or unacceptable products (Asbestos AB, 71). Requirements that products be harvested, manufactured, or produced using a specific method or in accordance with general environmental standards will not meet this test, unless those production or processing methods (PPMs) have some impact on the physical qualities or performance of the product. Until Asbestos, there was some uncertainty over whether the reference to 'their related processes or production methods' in the definition of technical regulation could bring mandatory unincorporated PPM requirements within the purview of the TBTA. Negotiating history seemed to suggest that the inclusion of non-product PPMs was entertained for some time, but was ultimately rejected (WTO CTE Secretariat, 1995; Marceau and Trachtman, 2002: 860). The AB's emphasis in Asbestos on the physical characteristics or qualities of goods almost certainly signals a definition that endorses a regulatory distinction between PPM requirements that are 'incorporated' into the physical characteristics or qualities of a product, and those measures that have no physical impact on the end-product, so-called 'unincorporated PPMs'.

Resistance to technical regulations based on unincorporated PPMs derives from concerns about transboundary application of domestic preferences. These, according to many, are at best inconsiderate of differing endowments or preferences, and at worst ripe for protectionist abuse (Bhagwati, 1996: 13). The irony of Members' exclusion of PPMs within the definition of technical regulations, however, is that concerns over the protectionist or unilateralist abuse of unincorporated PPMs might actually be allayed by subjecting such measures to the strict disciplines of the TBTA. Ensuring that PPM-standards are subject to the disciplines of the TBTA would provide a more accountable and rulesbased approach to formulating such standards than the 'default' suite of GATT disciplines to which they are subject when the TBTA (or SPSA) does not apply.

If unincorporated PPMs are not technical regulations, the TBTA has no application. The GATT continues to apply to such measures, but this means that they are potentially subject to less rigorous disciplines than a physical product standard. Even where a PPM measure is construed to violate GATT Article XI as an import ban the party imposing the measure may seek to rely on a GATT Article XX exception. This had been a difficult burden for a responding party to satisfy, but in Korea-Beef and Asbestos, the AB laid out a new balancing test for 'necessity' under Article $\mathrm{XX}(\mathrm{b})$ and (d), which is potentially more flexible and less onerous than the 'least trade restrictive' interpretation of earlier disputes. AB jurisprudence on the operation of Article $\mathrm{XX}(\mathrm{g})$ also reflects a willingness to accommodate competing non-trade objectives. The AB upheld the GATT-consistency of the 
United States' unilateral unincorporated PPM in the proceedings dealing with enforcement of the original Shrimp-Turtle AB decision. This decision was a milestone as the first time in GATT or WTO history in which a PPM of this sort was upheld as consistent with GATT disciplines (Shrimp-Turtle Enforcement $\mathrm{AB})$. The party seeking to justify a GATT-inconsistent measure still bears the burden of proving an Article XX exception, so the decision is not a licence for protectionist abuse, and every case will still depend on its unique circumstances. In general, however, it appears that PPM measures could be more easily justified under GATT than under the TBTA.

The harmful impact of production or manufacture is one of the major factors that underpins product regulation (Marceau and Trachtman, 2002: 861; Trachtman, 2003a: 62). Exclusion of such regulations from the TBTA leaves a significant gap. The TBTA is a powerful force in promoting adoption of international standards, and if regulatory and market needs dictate a focus on unincorporated PPMs, excluding those measures from the TBTA will reduce the impetus towards harmonized PPM standards. This is potentially inconsistent with the TBT Committee's own principles, which provide that 'international standards need to be relevant and to effectively respond to regulatory and market needs, as well as scientific and technological developments in various countries' (WTO CTBT, 2000).

This inconsistency is compounded by the fact that ISO, one of the TBTA's principal international standards bodies, has developed voluntary standards for quality assurance management systems (ISO 9000) and environmental management systems (ISO 1400), both unincorporated PPMs. A significant portion of the notifications to the Committee on Technical Barriers to Trade have involved national rules on such management systems. (WTO CTE Secretariat, 1999). ISO 9000's and 14000's status may have to be clarified if members make its implementation compulsory for some products or producers or if it becomes a de facto requirement (Murray, 1997: 580, note 19). Since the TBTA's primary concern is to prevent the proliferation of different national measures, it would be an unsatisfactory situation if unincorporated PPMs measures that were reflected in international standards were caught by TBTA disciplines, but purely domestic PPM measures were not.

\section{Labelling}

While PPM regulations themselves may fall outside the scope of the TBTA, PPMbased labelling schemes are far more likely to be considered technical regulations. The definition of technical regulation set out earlier includes 'symbols, packaging, marking or labelling requirements as they apply to a product, process or production method' (TBTA, Annex 1, 1). Some take the view that only labelling schemes relating to incorporated PPMs can be brought within the TBTA - essentially that the second sentence of the definition ("product, process or production method') should take colour from the first ('product or related process 
or production method') (Appleton, 1997, 93, 125; Bartenhagen, 74). This would leave pure PPM schemes for assessment under GATT.

The negotiating history of the TBTA suggests that parties did not intend labelling schemes based on unincorporated PPMs to be subject to the TBTA (WTO CTE Secretariat, 1995; Appleton, 1997: 93; Chang, 1997: 140-147). But it is impracticable for schemes that employ a mix of product and process labelling criteria to have some elements of the scheme subject to TBTA disciplines and others covered only by GATT. Despite this potentially illogical and clumsy operation, exclusion of labels based on PPM-criteria is the generally accepted academic and diplomatic view, especially among developing countries (Bartenhagen, 1997: 75; Appleton, 1997: 93; Marceau and Trachtman, 2002: 861, notes 94-195). The alternative view is that the second sentence of the definition clarifies the particular application of the TBTA to labelling requirements. On this reading, regardless of whether the criteria by which labels are awarded are PPM-based, all labelling schemes nonetheless fall within the scope of the TBTA (Ward, 1997: 143; Marceau and Trachtman, 2002: 861-862, 876). This acknowledges that a label (or packaging) is attached to and an intrinsic part of the product itself, regardless of the criteria by which the label is awarded or the warnings/statements it makes (Bartenhagen, 1997: 80). In Asbestos and Sardines, the AB decided that to fall within the scope of the TBTA, product requirements must apply to, but need not be intrinsic to, the product itself (Asbestos AB, 67; Sardines AB, 189). This may suggest an opening for the acceptance of PPM-based labelling schemes as technical regulations within the scope of the TBTA.

\subsection{TBTA disciplines for adopting international standards}

For measures that constitute TBTA technical regulations, the Agreement imposes a range of substantive and procedural disciplines on Members. TBTA Article 2.1 synthesizes the national treatment and most-favoured nation principles contained in GATT Articles I and III into a single non-discrimination obligation in respect of like products. Members are also required to avoid creating unnecessary obstacles to trade and to adopt the least trade restrictive means of achieving legitimate objectives (TBTA Article 2.2). These obligations have been analysed in detail elsewhere (Marceau and Trachtman, 2002: 874-875; Neumann and Tuerk, 2003). The following discussion therefore focuses on the provisions dealing with the adoption of international standards as domestic technical regulations.

The TBTA does not mandate harmonization of product standards, but provides strong incentives for the adoption of international standards. Article 2.4 requires Members to use international standards as a basis for technical regulations, where standards exist, but it permits higher standards in some circumstances. Members may adopt their own measure where no international norm has been established or where the international measure would be ineffective or inappropriate to fulfil a particular policy objective, 'for instance because of fundamental climatic or geographical factors or fundamental technological problems' (TBTA, Articles 2.2 and 
2.4). Technical regulations that accord with international standards are rebuttably presumed to be consistent with the TBTA's obligation to avoid unnecessary obstacles to trade (TBTA, Article 2.5).

This provision was contested in Sardines because the EC Regulation's restrictive naming standards departed from the standards set by the Codex Alimentarius Commission (Codex). Codex adopted a standard for canned sardines and sardinetype products in 1978 and revised it in 1995 ('Codex Stan 94'). Codex Stan 94 set quality and minimum content standards for products containing fish and regulated product naming and labelling. Under Codex Stan 94, the name 'sardines' was reserved exclusively for the species Sardina pilchardus, but other species on the list could use the name 'sardines' in conjunction with a country, regional or common name qualifier (Codex Stan 94, Article 6.1.1). Peru argued that the EC Regulation prohibited the marketing of Peruvian Sardinops Sagax as 'Pacific Sardines', and that this was inconsistent with Codex Stan 94 as the relevant international standard. Accordingly, it argued that the EC Regulation was inconsistent with TBTA Article 2.4. This claim raised several important issues for the operation of the TBTA standardization obligation.

\section{TBTA application to pre-existing product requirements}

The Sardines dispute clarified that WTO members are obliged to review technical regulations that predate the WTO Agreement upon the introduction of new international standards. Article 2.4 says that 'where technical regulations are required ... they shall be based on international standards'. This language is capable of implying a temporal trigger ('at the time regulations are required') or a circumstantial trigger ('in situations where regulations are required') for the obligation to use international standards. Peru advocated a circumstantial trigger, arguing that the obligation refers to all on-going circumstances that require regulation, even where those regulations are already in place. ${ }^{5}$

The equivalent harmonization provision of the SPSA was considered in the Hormones dispute. In Hormones, the AB concluded that the international standards provision of the SPSA applied to all existing and future domestic measures, there being no evidence of an intention to exempt existing measures from SPSA disciplines (Hormones AB, 128). This decision was based in part on the language of the SPSA, which refers to both 'adopting or maintaining' SPS measures, but more broadly on a contextual reading of the SPSA's obligations. This context included reference to Article XVI:4 of the WTO Agreement, which requires Members to 'ensure the conformity of its laws, regulations and administrative procedures with its obligations as provided in the [covered] agreements'.

5 The third party submissions of Canada, Chile, Colombia, Ecuador, and the United States all supported this approach. The issue was, however, essentially moot, since the EC Regulation was also inconsistent with the TBTA's predecessor the Standards Code, which had been in force when the EC Regulation came into effect. Sardines Panel, 5.6. 
In Sardines, the EC advanced an interpretation of the TBTA similar to the one it had unsuccessfully advocated for the SPSA in Hormones. It argued that it need only consider international standards where a new technical regulation was being considered and that Article 2.4 of the TBTA did not apply to measures adopted before the introduction of international standards (Sardines AB, 199). It relied on the general principle of treaty interpretation against retroactivity, claiming that the preparation and adoption of its Regulation was an 'act which took place before the entry into force' of the TBTA (Sardines AB, 32). The Vienna Convention on the Law of Treaties provides that such measures cannot be affected without express treaty language creating retroactive operation (Vienna Convention, Article 28).

It might be argued that the SPSA provision is more complex than the TBTA because of the additional requirements of risk assessment and scientific basis. Moreover, the obligation not to 'maintain' measures inconsistent with the SPSA is absent from the TBTA, so it might be argued that the SPSA is more explicit in its intended retroactivity. But these differences in language and process appear not to have been decisive in the Sardines AB decision. Rather, the AB relied on the similarities in the language of the two agreements (Sardines AB, 205-207). It found considerable textual support for application to existing measures, especially the centrality of the TBTA's obligation to harmonize national standards as widely as possible and to participate in standards development for products for which they have already adopted domestic measures (Sardines Panel, 7.76; Sardines AB, 212). Excluding existing measures from such a key provision would essentially establish grandfather rights for these measures, a consequence which WTO negotiators could not have intended (Sardines AB, 208, 215). The AB thus endorsed the Panel view that Article 2.4 imposed an ongoing obligation to reassess existing technical regulations in light of new or revised international standards (Sardines AB, 205).

In somewhat colourful language, the EC also argued that revision of domestic measures whenever new international standards are agreed would turn international standard-setting bodies into 'world legislators'. The Sardines Panel and $\mathrm{AB}$ regarded the EC's fear as overstated because the obligation to use international standards was a qualified one: a Member could simply choose not to introduce any technical regulation at all; could ignore 'irrelevant' standards; and need only use international measures 'as a basis' for domestic measures. Moreover, a Member need not follow international standards where they would be ineffective or inappropriate (Sardines Panel; Sardines AB, 216).

The AB's analysis appears to conflate two separate but related aspects of the TBTA's retroactive operation. The first issue is whether the TBTA applies to preexisting technical regulations at all, and the AB's acceptance that it does is not surprising. To decide otherwise, the $\mathrm{AB}$ would have had to reject a long tradition of equivalent reasoning under GATT law. The second question is what the TBTA requires in relation to existing measures. An affirmative conclusion to the first question still demands an analysis of the structure and operation of the agreement 
to answer the second question. It does not necessarily follow that all obligations apply to existing measures.

There is undoubted textual support, as well as precedent in GATT law, for the AB's conclusion. But, while it is instructive, GATT law regarding the presumption of retroactive operation is not directly relevant to the specific TBTA rule at issue. This is because all Members know of the general GATT disciplines when they became contracting parties and can be presumed to accept those known-disciplines from the outset. On the same reasoning, there is little doubt that all existing technical regulations must comply with the TBTA's general disciplines of necessity, least-trade restrictiveness, MFN, and NT. By contrast, however, the TBTA's delegation model introduces the possibility that Members must commit to obligations the content of which is not yet known. It might be argued that Article 2.3 already provides sufficient discipline on the relationship between existing regulations and new international standards, by obliging Members to review existing product requirements on a regular basis to assess whether they are still necessary and whether a less trade restrictive measure might serve the same ends. That review would presumably include an evaluation of any new or proposed international standards. Ultimately, the issue may be one of semantics or a matter of how frequent a 'periodic' review of existing measures should be, since the overall structure of the TBTA clearly contemplates some form of regular review of existing domestic measures in any event.

The obligation to re-visit domestic requirements once international measures are agreed would be unproblematic if international standards involved upward movement of product standards and if this obligation were matched by a positive duty of adoption on Members who previously had no standard. Currently, however, there is an asymmetry in the impact of the Sardines decision. The Sardines Panel made clear that a Member may simply decline to adopt any standard at all, if unhappy with international standards. This view was not questioned by the AB. This means that Members that have technical regulations in place may have to modify them to fit international standards, while other Members are free to ignore international measures and to keep domestic standards low or non-existent. Indeed, it appears that a Member that has declined to adopt any standard, even the relevant international standard, is still free to challenge the technical regulation of another Member that is more restrictive than the international standard. The Panel's and AB's comments may have provided some comfort on the question of how onerous a retroactive operation of the TBTA may be. They did nothing, however, to allay concerns that international standards are the de facto ceiling, rather than a floor for domestic regulation.

This lop-sided approach to harmonization runs counter to the TBTA's harmonization claims dealing with leakage and economies of scale. Indeed, Leebron makes it clear that harmonization to ensure the efficacy of domestic laws and prevent leakage typically contemplates adoption of some minimum (Leebron, 1996: 47). From the perspective of high standards countries, the potential 
intrusion of the TBTA into their choices, while it disregards the regulatory failure of low standards country, is both inconsistent and potentially biased against nontrade objectives. The current approach actually fuels the risk of regulatory stagnation, if not a race towards the bottom, since high-standards countries will be loathe to raise their standards even higher when others are not required to introduce even basic minima.

\section{Relevant international standards}

For the purposes of Article 2.4, an international standard is relevant to a domestic technical regulation if it bears upon, relates to, or is pertinent to the same subject matter (Sardines Panel, 7.69, Sardines AB, 230). In Sardines, the EC argued that Codex Stan 94 could not be considered a 'relevant' international standard for several reasons. It argued that Codex Stan 94 could not be an international standard because Codex Alimentarius failed the principle of consensus, as set out in the WTO CTBT's Principles for the Development of International Standards. Codex rules of procedure permit measures to be adopted by means of a formal vote, rather than by consensus, in some circumstances (Sardines Panel, 4.33). No evidence was presented to support the suggestion that adoption of Codex Stan 94 lacked consensus, but the EC's argument failed in any event, because the TBTA itself clearly contemplates the use of standards that have not been adopted by consensus:

Standards prepared by the international standardization community are based on consensus. This Agreement covers also documents that are not based on consensus. (TBTA Annex 1, 2, Explanatory Note; Sardines AB, 225)

An interesting aspect of this conclusion was the AB's emphasis that the TBTA's eschewal of a consensus requirement had no bearing on the internal workings of international standards bodies:

the fact that we find that the TBT Agreement does not require approval by consensus for standards adopted by the international standardization community should not be interpreted to mean that we believe an international standardization body should not require consensus for the adoption of its standards. That is not for us to decide. (Sardines AB, 227)

In making this observation, the $\mathrm{AB}$ may have been simply restating its jurisdictional competence. The comment might also be understood as the AB's latest attempt to demonstrate the WTO's capacity to respect other sources of international obligation (Reformulated Gasoline $\mathrm{AB}, 17$ ). The $\mathrm{AB}$ might also have been offering veiled advice to international standards bodies about the need for confidence in their decision-making processes and accountability. Viewed in this way, the AB's comments seek to enhance the effectiveness of the TBTA's harmonization objectives by ensuring that its mechanisms, including bodies to whom standard-setting functions are delegated, are best adapted to achieve their designated roles. 


\section{Interpreting the international standard}

Members must use international standards 'as a basis' for technical regulations. The $\mathrm{AB}$ followed its reasoning in Hormones, satisfied that a measure need not 'conform to' an international standard in order to be 'based on' it (Hormones AB, 163, adopted in Sardines AB, 242). It is sufficient if a technical regulation 'stands', is 'founded' or 'built' upon, or 'supported by' that standard. ${ }^{6}$ This requires 'a strong and very close relationship' between the two, such that the international standard is the 'principal constituent', 'fundamental principle', or 'determining principle' of the national measure (Sardines AB, 245). This relationship could not exist where the national measure and international standard are inconsistent or contradictory (Sardines AB, 248).

The EC argued that its Sardines regulation was essentially based upon Codex Stan 94, as understood by reference to its negotiating history rather than its plain meaning (Sardines Panel, 4.45; 7.94-7.95). The Panel and AB focussed on the final text of Codex Stan 94 to conclude that the EC Regulation directly contradicted the international standard (Sardines Panel, 7.95, Sardines AB, 239, 256, 258). The language of Codex Stan 94 is fairly clear, but it is of some concern that the Panel declined to clarify the correctness of its interpretation with the Codex Commission itself. The TBTA's elevation of international standards to 'first-preference' status involves a delegation of regulatory power from the WTO to those bodies. Trachtman suggests that this delegation creates potential agency problems for the WTO in ensuring that their international 'agents' are faithful to the WTO's objectives (Trachtman, 2003b: 31). Permitting the WTO dispute settlement tribunals to have the last word in deciding what those delegates said in their international standards overcomes this concern, but it hardly engenders confidence in the even-handedness of the process. The decision not to seek Codex's input was understandable in relation to the language of Codex Stan 94, but, as a matter of broad principle, it is of concern that a WTO Panel is able to determine unilaterally the application of international instruments created outside the WTO system. If this approach is taken in future disputes involving more ambiguous international standards, WTO dispute settlement tribunals could effectively determine the meaning of a standard, while the WTO Membership has avoided the political sensitivity of developing the standard in the first place (Marceau and Trachtman, 2002: 840; Trachtman, 2003a: 72).

The WTO Dispute Settlement Understanding gives Panels the discretion to seek additional information (DSU, Article 13). It would be prudent to expect consultation with relevant 'experts' where interpretation of another organization's legal instrument, rather than factual information, is involved. Indeed, the best approach would be to introduce a rule of procedure to the effect that where a dispute

6 It remains to be seen whether more is required in order to show that a measure has been prepared 'in accordance with' the international standard, in order to enjoy Article 2.5's presumption that it does not constitute an unnecessary obstacle to trade. 
involves interpretation of international standards, the secretariats of the relevant standards body must be consulted as technical experts within Article 13 of the DSU, to confirm the standard's intended meaning. Again, enhancing the mechanisms of harmonization in this way will assist in winning public support for the TBTA's over-arching goals.

\subsection{Article 2.4 Second limb - Not using international standards}

\section{Burden of proof}

Members must base technical regulations on relevant international standards 'except where they would be ineffective or inappropriate to achieve a legitimate objective' (TBTA Article 2.4, emphasis added). Similar language in the SPSA has been held to establish no general rule in favour of adopting the international standard (Hormones AB, 104). Despite the Hormones decision, the Sardines Panel took a literal reading of this text and decided that the TBTA language created a general rule in favour of international standards and provided an exception to that rule. This approach placed the burden of proving the exception on the EC, as the party claiming it (Sardines Panel, 7.50, citing Wool Blouses AB, 335). Accordingly, once Peru had shown that a technical regulation and a relevant international standard existed, and that the regulation was not based upon the international standard, the EC had to demonstrate that the international standard was ineffective or inappropriate to achieve its legitimate objectives of consumer information. The Panel justified its departure from the Hormones AB's approach to the SPSA on the basis that the SPSA set up a discrete alternative mechanism for national standard setting, involving risk assessment and sound science, that was not merely an exception to a general rule in favour of harmonization (Sardines Panel, 7.50, note 70).

The AB preferred to focus on the similarities between the SPSA and TBTA to conclude that there was no 'general rule-exception relationship' in TBTA Article 2.4 (Sardines AB, 274-275). Accordingly, for TBTA disputes involving a claim of non-compliance with international standards, the complaining party bears the burden of proving non-compliance with the international standard, plus the effectiveness and appropriateness of those standards to achieve the legitimate objective of the technical regulation (Sardines AB, 282). Any practical difficulties that the complaining party might encounter in identifying the legitimate objective or showing the measure's ineffectiveness or inappropriateness should be overcome by the procedural and transparency safeguards in the TBTA, such as the compulsory system of information provision established in TBTA Article 2.5; the national inquiry point that each Member is required to establish under Article 10.1; and information obtained during the dispute settlement proceedings themselves (Sardines AB, 277-280).

The AB's rejection of a 'general rule-exception relationship' in respect of international standards accords a greater degree of deference to sovereign policy choices and reduces the potential dominance of international standards. Placing on 
the complaining party the burden of proving inconsistency with all of Article 2.4 will make it easier for Members to maintain higher domestic measures. It will fall to the complaining Member to adduce evidence either that the policy objectives were not legitimate (a difficult task), or that the international standards were capable of fulfilling those objectives and well suited to doing so. Given that the TBTA imposes no reciprocal obligation on members to 'upwardly harmonize' technical standards and adopt international standards, the AB's approach to allocating the burden of proof probably achieves an appropriate compromise. It certainly highlights the selectivity of its literal reading of WTO texts (Appleton and Heiskanen, 2003), but it is nonetheless reassuring for observers who are fearful of excessive WTO intrusion into domestic regulatory autonomy.

Unfortunately, the Sardines decision casts no light on the final phrase in Article 2.4, which identifies some illustrative foundations for the 'inappropriateness or ineffectiveness' of international standards. The list refers to 'fundamental geographical or climatic factors or fundamental technological problems'. It makes no allowances for differences in demographic factors, cultural preferences or perceptions or tolerance of risk. While it is framed to be inclusive not exhaustive (cf. Wallach, 2002: 831), it remains to be seen whether the specified factors will colour the legitimacy of other possible reasons for rejecting international standards.

\section{Legitimate regulatory objectives and implementation}

Recognizing that regulatory diversity may stem from legitimate differences between Members, the TBTA generally leaves it to individual Members to determine which policy objectives they will pursue (TBTA Article 2.4). Article 2.2 recognizes the legitimacy of national security requirements; the prevention of deceptive practices; and protection of human health or safety, animal or plant life or health, or the environment. This list is non-exhaustive. The TBTA Preamble also provides that Members should not be prevented from taking measures to achieve protection 'at the levels it considers appropriate', suggesting that objectives may be pursued at higher levels of protection than is provided by international standards. ${ }^{7}$

Based on their approach in GATT disputes involving trade restrictions for domestic policy purposes, dispute settlement tribunals are likely to scrutinize the legitimacy of claimed objectives, mindful that a higher level of deference is shown to domestic policy objectives than to the means by which those objectives are advanced (Sardines Panel, 7.122). In Sardines, the EC purported to introduce its

7 An interesting issue that remains to be clarified is whether a requirement will be implied into the TBTA of consistency in the of levels of protection that a Member selects for products or activities posing similar risks, akin to Article 5.5 of the SPSA. (Hormones AB, 213; Salmon AB, 158). The AB has recognized that risks are often identified on an ad hoc basis, so that Article 5.5 is not a requirement for absolute or perfect consistency. What is scrutinized is arbitrary or unjustifiable inconsistencies. Hormones $\mathrm{AB}, 213$. The Sardines dispute did not consider this issue, but some element of regulatory consistency has been implied into GATT Article XX. Marceau and Trachtman (2002) suggest (at 847) that, given the similarities between that language and TBTA article 2.2, an equivalent obligation may be found in that provision too. 
naming regulation in order to ensure market transparency, consumer protection, and fair competition. Peru acknowledged that these were all legitimate policy goals, so this aspect of the EC claim was not in issue, but the means by which that objective was pursued were examined closely.

\section{Assessing effectiveness and appropriateness}

A measure that is not based on a relevant international standard does not have to be both ineffective and inappropriate to achieve a legitimate policy objective in order to meet the requirements of Article 2.4. Members may depart from international standards that would be effective in achieving a policy goal, if they are not the most suitable or fitting means of achieving that goal (Sardines Panel, at 7.116-7.117; Sardines AB, at 286-288). Although the burden of proof falls initially on the complaining party to adduce evidence of effectiveness and appropriateness, as a practical matter the Member defending its technical regulations will ultimately have to demonstrate the inadequacy of international standards.

In Sardines, the EC claimed that Codex Stan 94 was ineffective or inappropriate in informing consumer decisions because it could confuse or mislead them as to the true content of canned fish. This claim rested on an assumption that European consumers in fact associated the term 'sardines' with only one species of fish, namely Sardina pilchardus. This assumption was said to derive from both expectations that pre-dated the EC Regulation and from those created by it. The EC adduced some evidence that earlier laws had mandated the naming of Sardinops sagax as 'pilchards' or 'pacific pilchards'. Peru submitted considerable evidence to contradict the EC's assertions that European consumers associated only Sardina Pilchardus with the name 'sardines' (Sardines Panel, 7.127). Neither the Panel nor the $\mathrm{AB}$ accepted that this evidence of national practice showed that naming Sardinops sagax 'Pacific sardines' in accordance with Codex Stan 94 would necessarily mislead consumers (Sardines Panel, 7.129-130; Sardines AB, 290). Nor did they permit the EC to rely on any expectation created by the operation of the disputed regulation itself.

An absence of evidence about consumer expectations made it difficult for the EC to maintain a claim based on misleading practices. In fact, the Regulation was almost certainly partially motivated by protectionist intent: the Preamble to the EC Regulation stated that the measure was 'likely to improve the profitability of sardine production in the Community, and the market outlets therefore...' (Sardines Panel, 5.15). ${ }^{8}$ The weakness of the EC's case in Sardines makes it hard to determine how the $\mathrm{AB}$ would approach more subtle claims about expectations formed by the very regulation under scrutiny. For example, one might well imagine

8 The weakness of the EC's justification is not unique to this dispute. Numerous WTO disputes involving reliance on policy arguments, be they environmental, human health, resource conservation or consumer protection, have suffered from similar inconsistencies. From an environmental protection/human health perspective, for example, there was evidence of some protectionist motive in the Tuna-Dolphin, Hormones, Reformulated Gasoline, Salmon, Varietals and Apples disputes. 
a dispute involving a measure of long standing, which has produced significant changes in consumer attitudes, such as smoking bans and seatbelt laws. It would be worrying if 'acquired legitimacy' were never to satisfy the requirements of the TBTA. The Sardines decision offers little guidance on whether the political difficulty of adopting an international standard can form the basis for a claim that the standard would be 'inappropriate'. These matters may have a significant impact on the success of the TBTA harmonization compromise, but they await further clarification.

The foregoing analysis shows that Members may select their own social policy objectives and introduce regulations to achieve those objectives, but should use international standards wherever they will be effective and appropriate. The interpretation of these standards, and assessment of a Member's compliance rests with the WTO dispute settlement tribunals. Future disputes will elaborate a Member's right to adopt higher standards as national priorities dictate. These obligations leave considerable scope for interpretation: while the choice of legitimate objectives remains with Member governments, open-ended criteria will enable dispute settlement tribunals to mould the kind of regulatory measures that Members may adopt (Arup, 2000: 76).

The achievement of the TBTA's objectives is intrinsically affected by its choice of harmonization mechanisms and institutions. The promotion of international standards is not necessarily the best mechanism for addressing all of the TBTA's harmonization claims, but may be the only device for avoiding leakage and achieving regulatory efficacy. Regardless of whether adoption of international standards is the ideal mechanism, the TBTA will founder if the institutions to whom it has delegated standard-setting functions fail to perform. The disciplines of the TBTA emphasize the importance of international standards, yet bodies like Codex and ISO have received little attention to date. Research is now starting to fill this gap. In light of the important role of international standards in the TBTA and its impact on domestic regulation, Part 3 of this paper recommends improvements to the TBTA's delegation model that would enhance the transparency, accountability, and credibility of new international standards and their sensitivity to non-trade priorities.

\section{The implication of the TBTA for international standards}

While the TBTA does not mandate adoption of international standards, the Sardines decision demonstrates that it is certainly easier for a Member to defend product requirements that are based on, or adapted to suit, international standards. As well as promoting harmonization of domestic product requirements, the delegation of standard-setting functions to other international bodies achieves 'political economies of scale' by allowing a pooling of Members' regulatory and technical resources (Howse, 2002: 101). Moreover, removing controversial standard-setting functions to international fora insulates Members from the pressure 
of domestic coalitions, albeit sometimes at the expense of national democratic processes (Leebron, 1996: 63-64). The device of quasi-legislative delegation also has the potential to address gaps in the WTO's subject matter competence in policy areas like health and environment (Marceau and Trachtman, 2002: 838).

These factors should provide a powerful incentive to Members to contribute to their development. The TBTA calls on Members to 'play a full part, within the limits of their resources, in the development of international standards for products for which they have adopted or intend to adopt regulations' (TBTA Article 2.6). The following discussion considers two aspects of the quality and appropriateness of international standards, namely the composition of standards bodies and the range of bodies that the TBTA recognizes.

\subsection{Composition and decision making}

The proviso to TBTA Article 2.6, that Members should contribute to standards setting within the limits of their resources, points to a key deficiency in the composition of current bodies, namely, their northern bias. The TBTA defines an international organization as one whose Membership is open to at least all WTO Members (TBTA, Annex 1, 4). It undermines the very basis of the TBTA's key harmonization mechanisms if that definition is purely theoretical because developing countries lack the resources and expertise to participate. While this north-south imbalance is hardly unique to standards bodies, their influential status in the new WTO regime has attracted increased attention to the problem (Wilson, 2001). Wilson suggests prioritizing the development of international standards for key areas that will deliver trade enhancement for both developed and developing countries, thus enabling developing countries to concentrate their resources and representation. The FAO has acknowledged the need to build the capacity of developing countries in Codex (FAO, 2002, 29) and a recent World Bank-Doha Development fund initiative, the 'Standards and Trade Development Facility', is aimed at improving developing country representation. The success of the developments should be monitored closely. The SPS committee has this function in relation to international SPS standards, but no such role is given to the Committee on Technical Barriers to Trade, so there is no formal process for assessing improvements in the functioning of TBT standards bodies.

A corollary of the northern bias is the over-representation of industry representatives on national delegations, creating internal tensions over who 'represents' a nation (Hauselmann, 1996; Consumers International, 1999; Maskus and Wilson, 2000; Wilson, 2001: 12; Wallach, 2002: 835-837). This industry bias also manifests itself in the departmental lead agency representation - usually headed by trade or agriculture officials, rather than health or environment and in the general preference for an 'experts group' model of standards development (Piciotto, 2003). These developed country, industry, and 'expert' biases in the composition of standards bodies compound the risks inherent in their weaker procedural transparency and voting requirements. 
Removing the need for consensus in favour of a majority vote certainly makes standard setting easier, and insulates the WTO from criticism. It comes at a cost, however, to democratic decision making, which could ultimately undermine the legitimacy of international standards (Marceau and Trachtman, 2002: 840; Trachtman, 2003a: 72; in relation to SPSA standards bodies, Stewart and Johansen, 1998: 45, 52). Broadening the composition of standard-setting bodies and improving their decision-making procedures would enhance the legitimacy of the resulting standards. It would make them more democratic and accountable, and enable them to accommodate perspectives that acknowledge the subjective and contingent nature of specialist knowledge.

Responding to these criticisms, the Committee on Technical Barriers to Trade (CTBT) has formulated criteria by which to determine whether an international standard can be used for TBTA compliance (WTO CTBT, 2000). The Principles for the Development of International Standards, Guides, and Recommendations, agreed as part of the TBT Committee's second triennial review, are designed to 'ensure transparency, openness, impartiality and consensus, effectiveness and relevance, coherence, and to address the concerns of developing countries' (WTO CTBT, 2000, 1). The Principles require that information about standards-bodies' work programs be made available to the public in Member countries, with opportunities for public input (WTO CTBT, 2000, 3-5). Membership of international standards bodies should be open to the relevant bodies of at least all WTO Members for every stage of standard setting, from policy development, to technical development, voting and dissemination (WTO CTBT, 2000, 6). Consensus procedures should be developed to resolve conflict in order to ensure the impartiality of decision-making procedures (WTO CTBT, 2000, 8-9). Principles 7 and 8 refer to the need for 'meaningful' opportunities to participate, and Principle 13 seeks to address the practical resource constraints that might eviscerate legal participation rights :

The impartiality and openness of any international standardization process requires that developing countries are not excluded de facto from the process.

(WTO CTBT, Principle 13)

Whatever the flaws in the current composition and decision-making processes of the international standards bodies, the delegation to them of TBTA harmonization functions creates another risk. There is the potential that bodies like Codex, ISO, and others, which existed long before the WTO, will now see themselves as mere agents of the WTO, disregarding or downplaying the non-trade priorities in their objectives. The danger in this is that trade concerns receive double consideration - once at the standard-setting stage and once at the TBTA-compliance stage, thereby 'diluting' the importance of legitimate non-trade policy objectives. This fear is not allayed by the CTBT's Principles, which call for international standards bodies to 'put in place procedures aimed at improving communication with the World Trade Organization' (Principle 11). Since the activities (if not 
the output) of these bodies still sit outside the jurisdictional competence of the WTO, at least in a formal sense, it might have made more sense for the CTBT to develop procedures by which it could communicate with them. A monitoring role like that given to the SPS committee would be most appropriate, although this would require amendment or interpretation of the WTO CTBT's power in the TBTA itself. The somewhat cavalier approach to relations with international standards bodies currently suggested by Principle 11 merely validates concerns that their standards will emphasize trade facilitation over non-trade priorities.

\subsection{Expanding the list of recognized standards bodies}

Much of the concern about the TBTA's harmonization framework is that it stifles legitimate diversity, limits regulatory autonomy, and offers little incentive for upward harmonization of regulatory requirements. The pre-eminence of international standards within the TBTA regime could, however, be used as an opportunity to elevate the importance of environmental protection or other noneconomic goals, by recognizing a broader array of international treaties as international standards'. The explicit acknowledgment of such instruments as 'relevant international standards' would help connect the WTO regime to policy linkage areas in a way that respects the status of both instruments and reconciles competing policy systems.

The efficacy of such an approach would depend on clear agreement over which body is responsible for determining whether there has been 'compliance' with the relevant 'standard'. In Sardines, the WTO Panel and AB reached their own conclusions about the proper interpretation of Codex Stan 94, despite requests by the EC to consult with Codex to confirm its meaning. The AB affirmed the Panel's discretion to consult, making clear that it was under no duty to do so (Sardines AB, 298-302, citing Hormones AB, 147, and Shrimp-Turtle, 104). The amendment of dispute settlement procedures requiring Panels to consult the relevant international body on questions of interpretation would satisfy this requirement.

Of course, very few international agreements could currently be adopted as international standards organizations because their applicability is constrained by whether they set 'product standards' as defined in the TBTA. For example most multilateral environment agreements (MEAs) set national targets for certain environmental objectives or procedures for changing national policy, rather than stipulating the contents of particular products. The conventions of the ILO similarly relate to workers' rights and conditions of employment. The AB's current reading of 'technical regulation' would exclude Agreements that govern production processes. As has been argued elsewhere in this paper, this narrow reading does a disservice to the ends of both trade enhancement and non-trade objectives, so a formal interpretation that includes PPMs in the definition should be preferred in any event. 
This proposal would be strongly resisted by WTO Members, especially given persistent attitudes towards including PPMs. It is set forth here, however, as a way of prompting re-consideration of the linkage question in the context of the TBTA's harmonization mechanisms, and reconciling the tensions between trade and other international laws, principles, practice, and standards. It could do so in a way that avoids the politics of compromise that seems to have beset negotiations on the WTO's trade-environment work program, by seeking to respect both sets of obligations. As with the AB's current interpretation of international product standards, it would not imply any obligation to join or accept the obligations of the international agreement. It would merely recognize that compliance with standards stipulated by those agreements satisfies the necessity requirement for Members who do comply, thus overcoming the 'party-non-party' tensions in the 'WTO/MEA' debate.

\section{Conclusions}

Harmonization necessarily comes at the expense of diversity. Only where that diversity is illegitimate or susceptible to abuse should it be eliminated. The WTO TBTA advocates harmonization of product standards and requirements to prevent their use for protectionist motives, to facilitate trade by creating the conditions for economies of scale, and to ensure the efficacy of domestic laws and promoting 'fair' trade by removing diversity that creates an 'unfair' obstacle. The relationship between the TBTA, international standards, and domestic regulatory autonomy is becoming clearer. Empirical research is underway to understand the trade effects of technical regulations and to catalogue the way in which specific international standards are developed. For now, the WTO AB's decisions provide us with important guidance on the policy and legal implications of TBTA harmonization provisions. The most notable issue to date is the exclusion from TBTA disciplines of a wide range of important domestic product regulations because they do not necessarily stipulate product characteristics or qualities. In particular, the apparent exclusion of unincorporated PPM requirements will leave regulations in these important areas of modern non-trade policy untouched by the TBTA, to be regulated by the GATT alone.

For regulations falling within the ambit of the TBTA, the Sardines Appellate Body decision confirmed the right of Members to select their own social policy objectives and introduce measures to achieve those objectives. The detailed contours of this right are not yet known. The focus of WTO scrutiny will continue to be on the manner in which those domestic priorities are given effect. The parallels with GATT Article XX analysis are obvious and the AB has demonstrated a willingness to 'cross-fertilize' its readings of Annex 1A agreements (Marceau and Trachtman, 2002: 813), but it is hard to predict how the differences in language and operation might or should affect TBTA interpretation. This cross-fertilization 
makes interpretation of the TBTA important for the guidance it might offer on other WTO Agreements.

Unlike the general criteria of MFN, national treatment and necessity, the TBTA obligation to base domestic technical regulations on relevant international standards is not found in GATT. The AB has confirmed the important role played by this obligation in the overall architecture of the TBTA. It applies to new measures as well as to those introduced before either the TBTA or the international standard came into effect, creating an on-going obligation of review and revision. The burden of demonstrating the suitability or appropriateness of an international standard to achieve domestic policy goals rests on a complaining Member and not the Member imposing the domestic requirement. In practice, however, Members will still have to explain their reasons for adopting a different approach.

This is problematic when interpretation of those measures rests not their authors, but with the WTO dispute settlement tribunals. Such an arrangement resolves potential agency problems created by the TBTA's delegation model, but inevitably views international standards through a trade lens. The expectation that a party will reconsider domestic laws when international standards are agreed is not balanced by a duty to consider the adoption of such international norms where no national standard is yet in place. This may advance the objectives of trade facilitation and transparency, but it does little to further the non-trade goals advanced by the international standard.

If international standards are to assume a greater position in domestic regulation for all WTO Members, it is essential that the membership and decisionmaking procedures of international bodies are subject to on-going review and improvement. Just as the TBTA requires review and evaluation of existing national standards when international norms are adopted, so too should the systems and institutions of international standard-setting be subject to ongoing re-evaluation, improvement, and, where necessary, replacement. If harmonization becomes the norm for other WTO disciplines such as services and investment liberalization, public scrutiny of the quality of international standards institutions and rules will increase. The call for review, monitoring, and accountability will only grow louder as the reach of international standards bodies expands.

Harmonization of product regulations to achieve non-trade policy need not be downward. Indeed, with a true commitment to using the WTO regime to achieve sustainable development, Members could recognize a range of international environmental, labour and other agreements as relevant international standards. This would mean that domestic laws implementing those agreements were presumptively consistent with the TBTA's necessity obligation. Expanding the stable of international standards bodies could ensure that international harmonization enhances, rather than erodes, WTO handling of policy linkages. 


\section{References}

\section{WTO Disputes}

Australia-Measures Affecting Importation of Salmon, Report of the Appellate Body, WT/DS18/AB/R, 6 November 1998 (Salmon AB).

European Communities - Regime for the Importation and Sale of Bananas, Report of the Appellate Body, WT/DS27/AB/R, 9 September 1997 (Bananas AB).

European Communities - Measures Concerning Meat and Meat Products, WT/DS26/AB/R and WT/ DS48/AB/R, adopted 13 February 1998 (Hormones AB).

European Communities - Measures Affecting Asbestos and Asbestos-Containing Products, Reports of the Panel WT/DS135/R (Asbestos Panel); Report of the Appellate Body, WT/DS135/AB/R (Asbestos $\mathrm{AB})$.

European Communities - Trade Description of Sardines WT/DS231/R, 22 May 2002 (Sardines Panel); WT/DS231/AB, 26 September 2002 (Sardines AB).

European Communities - Measures Affecting the Approval and Marketing of Biotech Products, DS291, DS292, DS293, First written submission by the European Communities.

Japan-Measures Affecting Agricultural Products, Appellate Body Report, WT/DS76/AB/R, adopted 19 March 1999 (Varietals AB).

Japan-Measures affecting the importation of apples, Appellate Body Report, WT/DS245/AB/R, 15 July 2003 (Apples AB).

United States - Import Prohibition of Certain Shrimp and Shrimp Products, Report of the Appellate Body, adopted 6 November 1998, WT/DS58/AB/R (Shrimp-Turtle AB).

United States - Import Prohibition of Certain Shrimp and Shrimp Products, Recourse to Article 21.5 of the DSU by Malaysia, Report of the Appellate Body, 22 October 2001, WT/DS58/AB/RW (Shrimp-Turtle Enforcement AB).

United States - Measures Affecting Imports of Woven Wool Shirts and Blouses from India, Report of the Appellate Body, WT/DS33/AB/R, adopted 23 May 1997 (Wool Blouses AB).

United States - Restrictions on Imports of Tuna, Report of the Panel, GATT Doc DS 21/R (1991) 40S/155 (unadopted), reprinted in (1991) 30 ILM 1594 (Tuna-Dolphin I).

United States - Restrictions on Imports of Tuna, Report of the Panel, GATT doc DS 29/R (1994) (unadopted) reprinted in (1994) 33 ILM 842 (Tuna-Dolphin II).

United States - Standards for Reformulated and Conventional Gasoline, Report of the Appellate Body, WTO Document WT/DS2/AB/R, 29 April 1996, adopted 20 May 1996 (Reformulated Gasoline $\mathrm{AB})$.

Secondary materials

Appleton, A. (1997), Environmental Labelling Programs: International Trade Law Implications, The Hague: Kluwer Law International.

Appleton, A. and V. Heiskanen (2003), 'The Sardines Decision: Fish Without Chips?' paper presented to the seminar A New Constellation: SPS, TBT and the Codex Alimentarius in Light of the Hormones and Sardines Cases, University of Geneva, 14 March (copy on file with author).

Arup, C. (2000), The New World Trade Organization Agreements: Globalizing Law Through Services and Intellectual Property, Cambridge: Cambridge University Press.

Bartenhagen, E. (1997), 'The Intersection of Trade and the Environment: An Examination of the Impact of the Technical Barriers to Trade Agreement on Ecolabelling Programs', 17 Virginia Journal of Environmental Law, 51.

Bhagwati, J. (1996), ‘The Demands to Reduce Domestic Diversity among Trading Nations' in J. Bhagwati and R. Hudec (eds.) (1996), Fair Trade and Harmonization: Prerequisites for Free Trade? Vol. I: Economic Analysis, Cambridge, MA: MIT Press, p. 9.

Bhagwati, J. and T. N. Srinivasan (1996), 'Trade and the Environment: Does environmental Diversity Detract from the Case for Free Trade?', in J. Bhagwati and R. Hudec (eds.), Fair Trade and Harmonization: Prerequisites for Free Trade? Vol. I: Economic Analysis, Cambridge, MA: MIT Press, p. 15. 
Chang, S. (1997), 'GATTing a Green Trade Barrier - Ecolabelling and the WTO Agreement on Technical Barriers to Trade', 31 Journal of World Trade, 137.

Christoforou, T. (2000), 'Settlement of Science-Based Trade Disputes in the WTO: A Critical Review of the Developing Case Law in the Face of Scientific Uncertainty', 8 NYU Env. LJ, 624.

Consumers International (1999), 'Ensuring Food Safety - A Questions of Standards', The Work of the Codex Alimentarius Commission.

FAO (2002), 'Response to the Independent Review of the Codex Alimentarius Commission', 29, www.fao.org

Hauselmann, P. (1996), 'ISO Inside Out', WWF International Discussion Paper, Gland.

Howse, R. (2000), 'Democracy, Science and Free Trade: Risk Regulation on Trial at the World Trade Organisation', 76 Michigan Law Review, 2329.

- (2002), 'From Politics to Technocracy - and Back Again: The Fate of the Multilateral Trading Regime', American Journal of International Law - Symposium: The Boundaries of the WTO, 94.

Leebron, D. (1996), 'Lying Down with Procrustes: An Analysis of Harmonization Claims', in J. Bhagwati and R. Hudec (eds.), Fair Trade and Harmonization: Prerequisites for Free Trade? Vol. I: Economic Analysis, Cambridge, MA: MIT Press, p. 41.

Marceau, G. and J. Trachtman (2002), 'The Technical Barriers to Trade Agreement, the Sanitary and Phytosanitary Measures Agreement, and the General Agreement on Tariffs and Trade: A Map of World Trade Organization Law of Domestic Regulation of Goods', 36, Journal of World Trade, 811.

Maskus, K. and J. Wilson (2000), 'Quantifying the Impact of Technical Barriers to Trade: A Review of Past Attempts and the New Policy Context', paper presented to the World Bank Workshop on Quantifying the Trade Effect of Standards and Technical Barriers: Is it Possible? 27 April.

Murray, P. (1997), 'The International Environmental Management Standard, ISO 14000: A Non-Tariff Barrier or a Step to an Emerging Global Environmental Policy?', 18 University of Pennsylvania Journal of International Economic Law, 557.

Neumann, J. and E. Teurk (2003), 'Necessity Revisited: Proportionality in World Trade Organization Law After Korea-Beef, EC-Asbestos, and EC-Sardines, 37 Journal of World Trade, 199.

Picciotto, S. (2003), 'Private Rights vs Public Standards in the WTO', 10 Review of International Political Economy, 377.

Robertson, D. and A. Kellow (eds.) (2001), Globalization and the Environment: Risk Assessment and the WTO, Cheltenham: Edward Elgar.

Stewart, T. and D. Johansen (1998), 'The SPS Agreement of the World Trade Organization and International Organizations: The roles of the Codex Alimentarius Commission, the International Plant Protection Convention, and the International Office of Epizootics', 26 Syracuse Journal of International Law and Commerce, 27.

Trachtman, J. (2003a), 'Lessons for the GATS from Existing WTO Rules on Domestic Regulation', in A. Mattoo and P. Sauve (eds.), Domestic Regulation and Service Trade Liberalization, Washington, DC: World Bank/Oxford University Press, 57.

— (2003b), 'Addressing Regulatory Divergence Through International Standards', in A. Mattoo and P. Sauve (eds.), Domestic Regulation and Service Trade Liberalization, Washington, DC: World Bank/Oxford University Press, 27.

Transatlantic Consumer Dialogue (TACD) (2000), 'Principles for International Harmonization', Adopted by the TransAtlantic Consumer Dialogue, 12 February, available on the Public Citizen website: www.citizen.org.

Victor, D. G. (2000), 'The Sanitary and Phytosanitary Agreement of the World Trade Organinzation: An assessment after five years', 32 NYU Journal of International Law and Policy, 865.

Wallach, L. (2002), 'Accountable Governance in the Era of Globalization: The WTO, NAFTA, and International Harmonization of Standards', 50 University of Kansas Law Review, 823.

Ward, H. (1997), 'Trade and Environment Issues in Voluntary Eco-Labeling and Life Cycle Analysis', 6 RECIEL, 139.

Wilson, J. (2001), 'Bridging the Standards Divide: Recommendations for Reform from a Development Perspective’, World Bank Background Paper, World Bank Washington DC. 
WTO Committee on Technical Barriers to Trade (WTO CTBT) (2000), 'Decision on Principles for the Development of the International Standards, Guides and Recommendations with Relation to Articles 2,5 and Annex 3 of the Agreement', G/TBT/9 Annex 4, Principle 10, 13 November 2000.

WTO Committee on Trade and Environment (CTE) Secretariat (1995), 'Secretariat Note for the Committee on Trade and Environment, Negotiating History of the Coverage of the Agreement on Technical Barriers to Trade with Regard to Labelling Requirements, Voluntary Standards, and Processes and Production Methods Unrelated to Product Characteristics', WT/CTE/W/10, 29 August 1995.

WTO Committee on Trade and Environment (CTE) Secretariat (1999), 'Secretariat Note for the Committee on Trade and Environment, Item 4: Provisions of Multilateral Trading System with Respect to the Transparency of Trade Measures Used for Environmental Purposes and Environmental Measures and Requirements which have Significant Trade Effects', WT/CTE/W/118, 28 June 1999. 